\title{
Damage control surgery for splenic trauma: "preserve an organ - preserve a life"
}

\section{Control de daños en trauma esplénico: "preserva un órgano, preserva la vida"}

\author{
Carlos Serna ${ }^{(\mathbb{D}}$ José Julián Serna ${ }^{1,2,3,4}$ Yaset Caicedo $^{5^{(D}}$ Natalia Padilla $^{5}$ Linda M. \\ Gallego ${ }^{4}$ Alexander Salcedo ${ }^{1,2,3,4}$ Fernando Rodríquez-Holguín ${ }^{3}$ Adolfo González- \\ Hadad $^{1,2,6}$ Alberto García ${ }^{1,3,4}$ Mario Alain Herrera ${ }^{1,2}$ Michael W. Parra $^{(\mathbb{D}}$ Carlos A. \\ Ordoñez ${ }^{1,3,4}$ \\ ordonezcarlosa@gmail.com, carlos.ordonez@fvl.org.co
}

\begin{abstract}
1 Universidad del Valle, Facultad de Salud, Escuela de Medicina, Department of Surgery Division of Trauma and Acute Care Surgery. Cali, Colombia. 2 Hospital Universitario del Valle, Department of Surgery, Division of Trauma and Acute Care Surgery, Cali, Colombia. 3 Fundación Valle del Lili., Department of Surgery, Division of Trauma and Acute Care Surgery, Cali, Colombia. 4 Universidad Icesi, Cali, Colombia. 5 Fundación Valle del Lili, Centro de Investigaciones Clínicas (CIC), Cali, Colombia 6 Centro Médico Imbanaco, Cali, Colombia. 7 Broward General Level I Trauma Center, Department of Trauma Critical Care, Fort Lauderdale, FL - USA,
\end{abstract} \begin{abstract}
Salcedo A, Rodríguez-Holguín F, González-Hadad A, García A, Herrera MA, Parra MW, Ordoñez CA. Damage control surgery for splenic trauma:"preserve an organ - preserve a life". Colomb Méd (Cali), 2021; 52(2):e4084794 http://doi. org/10.25100/cm.v52i 2.4794
\end{abstract}

Caicedo Y, Padilla N, Gallego LM,

Received : 26 Mar 2021

Revised: 14 Apr 2021

Accepted : 06 May 2021

Published: 07 May 2021

Keywords:

Spleen; injury severity score; splenectomy; laparotomy; focused assessment with sonography for trauma; advanced trauma life support care; damage control surgery; negativepressure wound therapy; balloon occlusion; REBOA

Palabras clave:

Bazo; puntuación de gravedad de la lesión; esplenectomía; laparotomía; evaluación enfocada con ecografía para traumatismos; atención de soporte vital avanzado para traumatismos; cirugía de control de daños; terapia de heridas con presión negativa; oclusión con globo; REBOA

\section{Abstract}

The spleen is one of the most commonly injured solid organs of the abdominal cavity and an early diagnosis can reduce the associated mortality. Over the past couple of decades, management of splenic injuries has evolved to a prefered non-operative approach even in severely injured cases. However, the optimal surgical management of splenic trauma in severely injured patients remains controversial. This article aims to present an algorithm for the management of splenic trauma in severely injured patients, that includes basic principles of damage control surgery and is based on the experience obtained by the Trauma and Emergency Surgery Group (CTE) of Cali, Colombia. The choice between a conservative or a surgical approach depends on the hemodynamic status of the patient. In hemodynamically stable patients, a computed tomography angiogram should be performed to determine if non-operative management is feasible and if angioembolization is required. While hemodynamically unstable patients should be transferred immediately to the operating room for damage control surgery, which includes splenic packing and placement of a negative pressure dressing, followed by angiography with embolization of any ongoing arterial bleeding. It is our recommendation that both damage control principles and emerging endovascular technologies should be applied to achieve splenic salvage when possible. However, if surgical bleeding persists a splenectomy may be required as a definitive lifesaving maneuver. 
Copyright: @ 2021 Universidad del Valle (c) (b) $(-)$

Conflicts of interest:

The authors declare that they have no conflict of interest.

\section{Acknowledgments:}

We would like to extend our gratitude to the anatomical illustrator Fabian R. Cabrera P., Professor of the Design Department of the Integrated Arts Faculty, for the illustrations and cover design

\section{Corresponding author:}

Carlos A. Ordonez, MD, FACS. Division of Trauma and Acute Care Surgery, Department of Surgery. Fundación Valle del Lili. Cali, Colombia; Division of Trauma and Acute Care Surgery, Department of Surgery, Universidad del Valle, Cali, Colombia; Universidad Icesi, Cali, Colombia.

e-mail: ordonezcarlosa@gmail.com, carlos.ordonez@fvl.org.co

\section{Resumen}

El bazo es uno de los órganos sólidos comprometidos con mayor frecuencia en el trauma abdominal y el diagnóstico oportuno disminuye la mortalidad. El manejo del trauma esplénico ha cambiado considerablemente en las últimas décadas y hoy en día se prefiere un abordaje conservador incluso en casos de lesión severa. Sin embargo, la estrategia óptima para el manejo del trauma esplénico en el paciente severamente traumatizado aún es controvertida. El objetivo de este artículo es proponer una estrategia de manejo para el trauma esplénico en pacientes politraumatizados que incluye los principios de la cirugía de control de daños en base a la experiencia obtenida por el grupo de Cirugía de Trauma y Emergencias (CTE) de Cali, Colombia. La decisión entre un abordaje conservador o quirúrgico depende del estado hemodinámico del paciente. En pacientes hemodinámicamente estables, se debe realizar una tomografía axial computarizada con contraste endovenoso para determinar si es posible un manejo conservador y si requiere angio-embolización. Mientras que los pacientes hemodinámicamente inestables deben ser trasladados inmediatamente al quirófano para empaquetamiento esplénico y colocación de un sistema de presión negativa, seguido de angiografía con embolización de cualquier sangrado arterial persistente. Es nuestra recomendación aplicar conjuntamente los principios del control de daños y las tecnologías endovasculares emergentes para lograr la conservación del bazo, cuando sea posible. Sin embargo, si el sangrado persiste puede requerirse una esplenectomía como medida definitiva para salvaguardar la vida del paciente.

\section{Remark}

\section{1) Why was this study conducted?}

This article aims to present a proposal for the management of splenic trauma in severely injured patients

\section{2) What were the most relevant results of the study?}

It is our recommendation that both damage control principles and emerging endovascular technologies should be applied to achieve splenic salvage when possible. However, if surgical bleeding persists a splenectomy may be required as a definitive lifesaving maneuver

\section{3) What do these results contribute?}

The spleen should be salvage when it will be possible. Splenectomy should not be the first option. 


\section{Introduction}

The spleen is one of the most commonly injured organs in blunt abdominal trauma but in penetrating trauma the incidence reaches only 7 to $9 \%$. The overall mortality of a splenic injury becomes significant when the diagnosis is delayed ${ }^{1-4}$. Over the past couple of decades, the optimal management of a splenic injury has undergone significant transformation and nowadays it has evolved to a preferred non-operative approach even in severely injured cases ${ }^{5}$. This approach seeks to preserve the spleen using strategies such as strict clinical observation and angio-embolization. However, the management strategy of hemodynamically unstable trauma patients with splenic injuries remains controversial ${ }^{6}$.

The Trauma and Emergency Surgery Group (CTE) of Cali, Colombia is made up of experts from the University Hospital Fundación Valle del Lili, the University Hospital del Valle "Evaristo García", the Universidad del Valle and Universidad Icesi, the Asociación Colombiana de Cirugía, the Pan-American Trauma Society and international specialists of the United States, Europe, Japan, South Africa, and Latin America. Through a collaborative effort, we have been able to summarize a group consensus that condenses the experience obtained during the past 30 years in the management of trauma, general surgery and critical care. The aim of this article is to delineate the experience obtained by our group in the surgical management of splenic trauma in severely injured patients by proposing a management strategy that includes basic principles of damage control surgery.

\section{Epidemiology}

The spleen is one of the most commonly injured solid organs of the abdominal cavity. Between 2014 and 2016, Coccollini et al. reviewed a total of 124 patients with splenic injuries and the most prevalent mechanism of injury was blunt trauma secondary to automotive traffic accidents, followed by falls. The median Injury Severity Score (ISS) was 27 (IQR: 5-75) and half of these patients had a positive extended focused assessment with sonography for trauma (E-FAST) during initial evaluation. Seventy-two percent of the patients had mild to moderate splenic injuries (AAST Grade I-III) and 28.2\% had severe injuries (AAST Grade IV-V). Nonoperative management was performed in 53\% (66) of the cases and $47 \%$ (58) required damage control surgery, of these 49 underwent splenectomy and 9 required open abdominal packing. The overall mortality rate was $10.5 \%{ }^{7}$. Teuben et al. performed a systematic literature review that included 608 patients with penetrating splenic trauma, in which the most prevalent mechanism of injury was gunshot wounds. Non-operative management was carried out in 14$33 \%$ of the cases and the overall mortality rate was $6-14 \%^{8}$.

\section{Initial approach and diagnosis}

Initial management must be directed towards the stabilization of the patient according to the Advanced Trauma Life Support (ATLS) guidelines which include the ABC's strategy. Both common femoral vein and artery lines should be placed. The choice between immediate surgical exploration or further extended imaging studies depends on the hemodynamic status of the patient. If the patient is hemodynamically stable or a transient responder a computed tomography angiogram (CTA) should be performed to determine if non-operative management is feasible and if angioembolization is required ${ }^{6,9}$. However, patients with persistent hemodynamic instability (sustained systolic blood pressure $\leq 70 \mathrm{mmHg}$ ) should be immediately transferred to the operating room for an exploratory laparotomy. During the initial laparotomy, immediate control of hemorrhage should be achieved by abdomen packing and the anesthesia staff should be given enough time to complete the ongoing damage control resuscitation, via prior activation of the institution's massive transfusion protocol. Only then, the magnitude and the anatomical involvement of the spleen should be quantified following the American Association for the Surgery of Trauma (AAST) classification (Table 1). 
Table 1. AAST classification of splenic injuries ${ }^{10}$

\begin{tabular}{cll}
\hline Grade & Type & \multicolumn{1}{c}{ Description of injury } \\
\hline I & Hematoma & Subcapsular, $<10 \%$ surface area \\
II & Laceration & Capsular tear, $<1 \mathrm{~cm}$ parenchymal depth \\
& Hematoma & Subcapsular, $10 \%-50 \%$ surface area Intraparenchymal, $<5 \mathrm{~cm}$ in diameter \\
III & Laceration & Capsular tear, $1-3 \mathrm{~cm}$ parenchymal depth that does not involve a trabecular vessel \\
& Hematoma & Subcapsular, $>50 \%$ surface area or expanding Ruptured subcapsular or parenchymal hematoma \\
& Laceration & $>3 \mathrm{~cm}$ parenchymal depth or involving trabecular vessels \\
IV & Laceration & Laceration involving segmental or hilar vessels producing major devascularization $(>25 \%$ of spleen $)$ \\
& Laceration & Completely shattered spleen \\
V & Vascular & Hilar vascular injury with devascularized spleen \\
\hline
\end{tabular}

In 2017, the World Society of Emergency Surgery (WSES) updated their guidelines for the diagnosis and management of splenic trauma, which includes the AAST Grade classification and the hemodynamic status of the patient (Table 2).

\section{Rationale}

Despite advances in trauma critical care, the optimal surgical management strategy of splenic trauma remains controversial. We propose a surgical management that takes into account damage control principles and the use of tools such as computed tomography angiogram, angioembolization and strict clinical monitoring.

\section{Computed Tomography Angiogram}

We propose that if the patient arrives hemodynamic unstable but is a transient responder a computed tomography angiogram should be performed to determine the extent of the injury and the presence of any other associated injuries. Depending on the computed tomography angiogram findings, the patient can undergo either non-operative management or an open approach ${ }^{11-13}$. Computed tomography angiogram has a reported sensitivity of $96 \%$ and specificity of $100 \%$ for the diagnosis of splenic injuries. For these reasons, the computed tomography angiogram prevents in $54 \%$ of cases, any unnecessary surgical interventions ${ }^{6,14}$.

\section{Angioembolization}

Endovascular control by angiography has been reported as an important factor in obtaining splenic salvage and the subsequent reduction in mortality rates from these injuries ${ }^{15,16}$. Moreover, some meta-analysis has proven that non-operative management with angioembolization is associated with higher rates of survival and the reduction of treatment failure rates in patients with AAST Grade IV-V injuries ${ }^{6,17}$.

\section{Damage Control Surgery}

Splenic packing is the most important surgical management tool that a surgeon possesses to achieve active surgical hemorrhage control in the severely injured trauma patient. If surgical bleeding persists, then reinforcement of the packing should be performed, and the patient should undergo angiography for embolization. If this option is not readily available, then immediate splenectomy should be performed ${ }^{10}$. Splenorraphy, partial splenectomy and surgical meshes have not proven any real advantage or efficacy in achieving true splenic salvage ${ }^{6}$. As a result, it is our recommendation that both principles of damage control resuscitation and damage control surgery should be combined with emerging endovascular technologies to achieve hemorrhage control and ultimately splenic salvage, when possible. 
Table 2. WSES Splenic Trauma Classification ${ }^{5}$

\begin{tabular}{lccc}
\hline & WSES Class & AAST & Hemodynamic Status \\
\hline Minor & WSES I & I & Stable \\
Moderate & WSES II & III & Stable \\
Severe & WSES III & IV-V & Stable \\
& WSES IV & I-V & Unstable \\
\hline
\end{tabular}

\section{Surgical Approach}

Based on our experience we propose a new algorithm for the management of splenic trauma:

STEP 1: Attention should be directed towards identifying all immediate life-threatening injuries following the $\mathrm{ABC}$ mnemonic of ATLS. Both a common femoral vein and artery lines are placed for intravenous access, blood pressure monitoring and the initiation of an aggressive damage control resuscitation.

STEP 2: All patients that arrive with hemodynamic instability (sustained systolic blood pressure $\leq 70 \mathrm{mmHg}$ ) or non-transient responders should have their common femoral arterial line changed over a guidewire to a femoral sheath, followed by placement of a Resuscitative Endovascular Balloon Occlusion of the Aorta (REBOA) in Zone 1. This procedure should be performed in the emergency room. The REBOA becomes an important resuscitative tool that ultimately prevents hemodynamic collapse while at the same time maintains coronary and cerebral perfusion. Additionally, the institution's massive transfusion protocol should be activated. If the patient is hemodynamically stable or a transient responder, a computed tomography angiogram should be performed to determine the extent of the damage and the presence of any other associated injuries. According to the findings, the patient can undergo either non-operative management or an open approach.

STEP 3: The hemodynamically unstable patient or the non-transient responder should be transferred immediately to the operating room for emergency exploratory laparotomy. If you are not trained or do not have a REBOA available at your institution, then we recommend aortic cross-clamping as soon as possible ${ }^{18}$.

STEP 4: During the exploratory laparotomy, the trauma surgeon should initially control all sources of ongoing surgical bleeding and bowel contamination. As soon as these are achieved, the magnitude of the splenic injury should be determined according to the AAST classification (Table 1):

$\circ$ AAST Grade I/II/III: These injuries require prompt splenic packing. Once bleeding control has been achieved, damage control surgery should be completed (Figure 1).

- AAST Grade IV: These injuries also require prompt splenic packing. If hemorrhage control is achieved, damage control surgery should be completed. However, if the hemorrhage persists and the patient remains hemodynamically unstable, then a splenectomy should be considered (Figure 2).

- AAST Grade V: Splenic injuries with complete destruction and/or devascularization require a splenectomy for hemorrhage control followed by damage control surgery (Figure 3).

STEP 5: Damage control surgery should be completed. Following splenic packing, the patient is left with an open abdomen and a negative pressure dressing is placed. Then, angiography with embolization of any ongoing arterial bleeding should follow. Subsequently, the patient should be transferred to the intensive care unit for correction of the lethal diamond.

STEP 6: If there is any suspicion of persistent bleeding a second angiogram with possible embolization should be considered. However, if the suspicion is associated with hemodynamic 


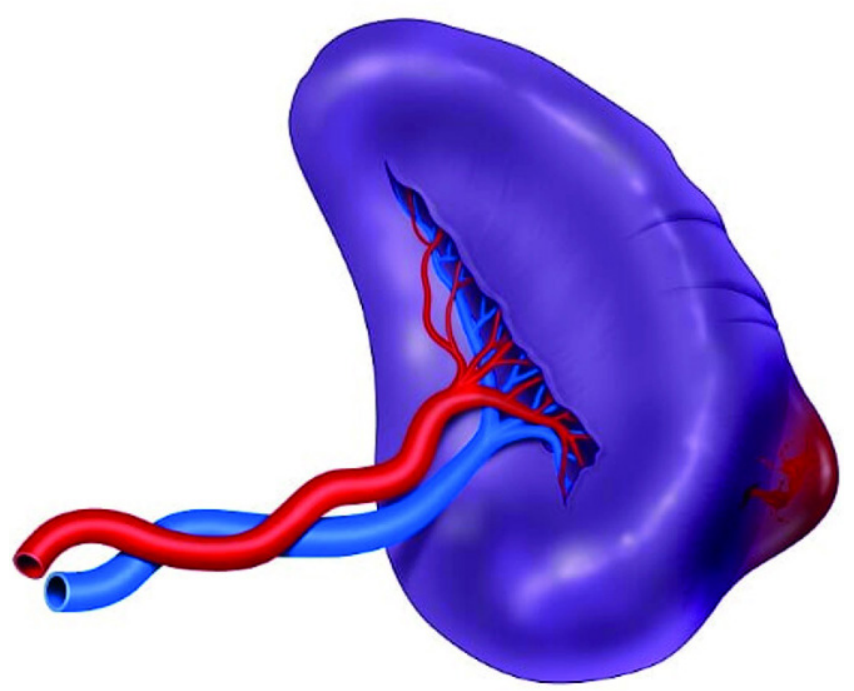

Figure 1. AAST Grade II Splenic Injury. Subcapsular splenic hematoma. These injuries require an early splenic packing. Once bleeding has been controlled, damage control surgery should be completed and the subsequent need for angiography with embolization should be assessed.

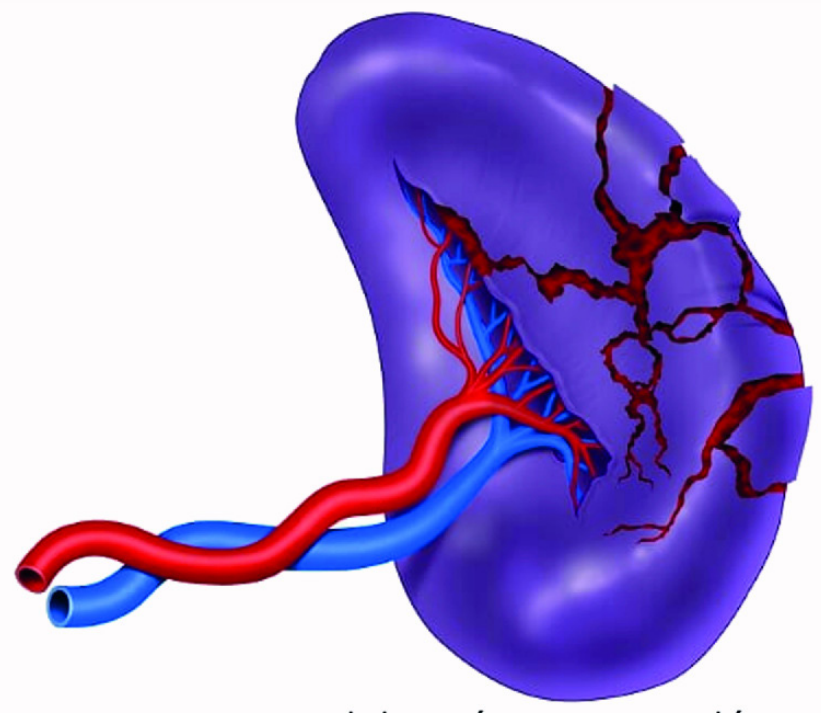

Figure 2. AAST Grade IV Splenic Injury. Massive parenchymal laceration without vascular involvement. These injuries also require prompt splenic packing. If hemorrhage control is achieved, damage control surgery should be completed, followed by angiography with embolization of any ongoing arterial bleeding. However, if the hemorrhage persists and the patient remains hemodynamically unstable, then a splenectomy should be considered.

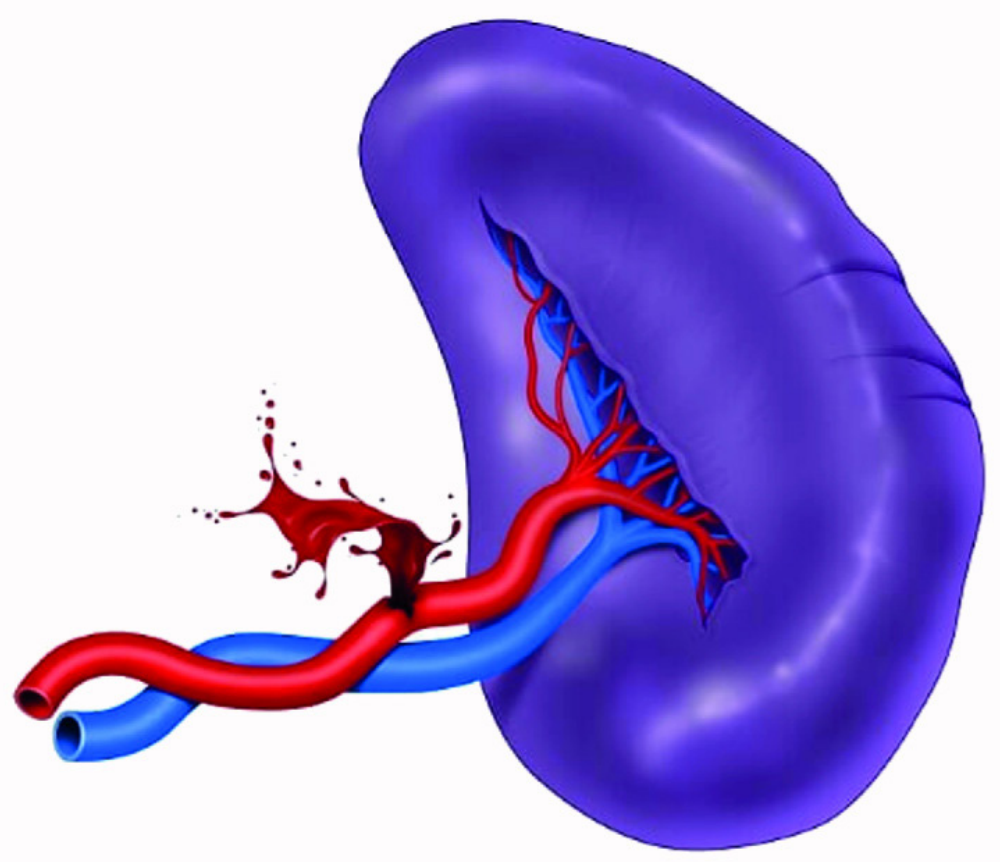

Figure 3. AAST Grade V Splenic Injury. Splenic artery involvement. Splenic injuries with complete destruction and/or devascularization require a splenectomy for hemorrhage control followed by damage control surgery. 
instability, the patient should be transferred immediately to the operating room for reintervention via exploratory laparotomy. In cases where the splenectomy has already been performed, selective hemostasis should follow and the abdomen should be re-packed and left

open with a negative pressure dressing. The patient should then be transferred back to the ICU for completion of damage control resuscitation.

STEP 7: Within 24 to 72 hours of aggressive hemostatic resuscitation in the intensive care unit, the patient should be taken back to the operating room for packing removal, abdominal washout and definitive abdominal wall closure. However, if splenic hemorrhage persists during this reintervention, packing should be reinstated and Step 5 repeated.

\section{Complications}

Non-operative management is the gold standard for hemodynamically stable blunt splenic trauma patients with a reported rate of therapeutic failure between $4-15 \%{ }^{19-22}$. The main complication is persistent bleeding which entails higher transfusion requirements and morbidity rates ${ }^{23-25}$.

Patients suffering from penetrating splenic trauma often have other associated intraabdominal injuries which can involve the pancreas, colon and diaphragm. Angioembolization in penetrating splenic trauma has an overall success rate of 73 to $100 \%{ }^{26-28}$. It is well established in the literature that as the degree of splenic injury increases also does the requirement of an open surgical management ${ }^{29}$. According to the AAST classification, Grade I injuries require open surgical management in 33\% of the cases and Grade V injuries in $84 \%$. The most dreadful post-operative complication of splenectomized patients is the development of an overwhelming post-splenectomy infection, which is caused by encapsulated organisms such as Streptococcus pneumoniae, Haemophilus influenzae type B, and Neisseria meningitidis. To avoid this complication, all patients who undergo splenectomy should receive a pre-established post-operative institutional vaccination protocol ${ }^{6,30-32}$.

\section{Conclusion}

The optimal management of splenic trauma in the severely injured patient is controversial. It is our recommendation that both principles of damage control resuscitation and damage control surgery should be combined with emerging endovascular technologies to achieve splenic salvage, when possible. However, if surgical bleeding persists a splenectomy should be considered as a definitive lifesaving maneuver.

\section{References}

1. Forsythe RM, Harbrecht BG, Peitzman AB. Blunt splenic trauma. Scand J Surg. 2006;95:146-51. Doi: $10.1177 / 145749690609500303$

2. Cales RH. Preventable trauma deaths. A review of trauma care systems development. JAMA. 1985;254:1059-63. Doi: 10.1001/jama.254.8.1059.

3. Olthof DC, Van Der Vlies CH, Joosse P, Van Delden OM, Jurkovich GJ, Goslings JC. Consensus strategies for the nonoperative management of patients with blunt splenic injury: A Delphi study. J Trauma Acute Care Surg. 2013;74:1567-74. Doi: 10.1097/TA.0b013e3182921627.

4. Petrone P, Peña MFA, Staffolani MJS, Brathwaite C, Axelrad A, Esparragón JC. Evolución en el tratamiento conservador del traumatismo esplénico contuso. Cirugía Española. 2017;95:420-7.

5. Coccolini F, Montori G, Catena F, Kluger Y, Biffl W, Moore EE, et al. Splenic trauma: WSES classification and guidelines for adult and pediatric patients. World J Emerg Surg. 2017;12:40. Doi: 10.1186/s13017-017-0151-4. 
6. Coccolini F, Fugazzola P, Morganti L, Ceresoli M, Magnone S, Montori G, et al. The World Society of Emergency Surgery (WSES) spleen trauma classification: A useful tool in the management of splenic trauma. World J Emerg Surg. 2019;14:30. Doi: 10.1186/s13017-019-0246-1.

7. Teuben M, Spijkerman R, Pfeifer R, Blokhuis T, Huige J, Pape HC, et al. Selective non-operative management for penetrating splenic trauma: a systematic review. Eur J Trauma Emerg Surg. 2019;45:979-85. Doi: 10.1007/s00068-019-01117-1.

8. Ordoñez CA, Badiel M, Pino LF, Salamea JC, Loaiza JH, Parra MW, et al. Damage control resuscitation: Early decision strategies in abdominal gunshot wounds using an easy "aBCD" mnemonic. J Trauma Acute Care Surg. 2012;73:1074-8. Doi: 10.1097/TA.0b013e31826fc780.

9. Ordoñez CA, Herrera-Escobar JP, Parra MW, Rodriguez-Ossa PA, Mejia DA, Sanchez Al, et al. Computed tomography in hemodynamically unstable severely injured blunt and penetrating trauma patients. J Trauma Acute Care Surg. 2016;80:597-603. Doi: 10.1097/TA.0000000000000975.

10. Moore E, Cogbill T, Malangoni M, Jurkovich G, Champion H, Gennarelli T, et al. Organ injury scaling, II: pancreas, duodenum, small bowel, colon and rectum. J Trauma. 1990;30:1427-9.

11. Smith HE, Biffl WL, Majercik SD, Jednacz J, Lambiase R, Cioffi WG. Splenic artery embolization: Have we gone too far? J Trauma. 2006;61:541-4. Doi: 10.1097/01.ta.0000235920.92385.2b.

12. Bessoud B, Denys A, Calmes JM, Madoff D, Qanadli S, Schnyder P, et al. Nonoperative management of traumatic splenic injuries: Is there a role for proximal splenic artery embolization? Am J Roentgenol. 2006;186:779-85. Doi: 10.2214/AJR.04.1800.

13. Haan JM, Biffl W, Knudson MM, Davis KA, Oka T, Majercik S, et al. Splenic Embolization Revisited: A Multicenter Review. J Trauma. 2004;56:542-7. Doi: 10.1097/01.TA.0000114069.73054.45.

14. Berg RJ, Inaba K, Okoye O, Pasley J, Teixeira PG, Esparza M, et al. The contemporary management of penetrating splenic injury. Injury. 2014;45:1394-400. Doi: 10.1016/j.injury.2014.04.025.

15. Skattum J, Naess PA, Gaarder C. Non-operative management and immune function after splenic injury. $\mathrm{Br} \mathrm{J}$ Surg. 2012;99:59-65. Doi: 10.1002/bjs.7764.

16. Leone G, Pizzigallo E. Bacterial infections following splenectomy for malignant and nonmalignant hematologic diseases. Mediterr J Hematol Infect Dis. 2015;7(1): e2015057. Doi: 10.4084/MJHID.2015.057.

17. Lee HJ, Cheng CT, Chen CC, Liao CA, Chen SW, Wang SY, et al. Increased long-term pneumonia risk for the trauma-related splenectomized population - a population-based, propensity score matching study. Surg (United States). 2020;167:829-35. Doi: 10.1016/j.surg.2020.01.006.

18. Ordoñez C, Garcia AF, Parra M, Valle AM del, Herrera-Escobar JP, Guzman-Rodriguez M, et al. Single-pass whole-body vs organ-selective computed tomography for trauma: timely diagnosis vs radiation exposure: an observational study. Panam J Trauma Crit Care Emerg Surg. 2020;9:26-31. Doi: 10.5005/jpjournals-10030-1262.

19. Ordoñez CA, García C, Parra MW, Angamarca E, Guzmán-Rodríguez M, Orlas CP, et al. Implementation of a new single-pass whole-body computed tomography protocol: is it safe, effective and efficient in patients with severe trauma? Colomb Med (Cali). 2020; 51(1): e4224. Doi: 10.25100/cm.v51i1.4224.

20. Shapiro MJ, Krausz C, Durham RM, Mazuski JE. Overuse of splenic scoring and computed tomographic scans. J Trauma. 1999;47:651-8. Doi: 10.1097/00005373-199910000-00008.

21. Rosati C, Ata A, Siskin GP, Megna D, Bonville DJ, Stain SC. Management of splenic trauma: A single institution's 8-year experience. Am J Surg. 2015;209:308-14. Doi: 10.1016/j.amjsurg.2014.06.034. 
22. Banerjee A, Duane TM, Wilson SP, Haney S, O'Neill PJ, Evans HL, et al. Trauma center variation in splenic artery embolization and spleen salvage: A multicenter analysis. J Trauma Acute Care Surg. 2013;75:69-75. Doi: 10.1097/TA.0b013e3182988b3b.

23. Requarth JA, D'Agostino RB, Miller PR. Nonoperative management of adult blunt splenic injury with and without splenic artery embolotherapy: A meta-analysis. J Trauma - Inj Infect Crit Care. 2011;71:898-903. Doi: 10.1097/TA.0b013e318227ea50.

24. Ordoñez C, Pino L, Badiel M, Sanchez A, Loaiza J, Ramirez O, et al. The 1-2-3 approach to abdominal packing. World J Surg. 2012;36:2761-6. Doi: 10.1007/s00268-012-1745-3.

25. Ordoñez CA, Rodríguez F, Parra M, Herrera JP, Guzmán-Rodríguez M, Orlas C, et al. Resuscitative endovascular balloon of the aorta is feasible in penetrating chest trauma with major hemorrhage: Proposal of a new institutional deployment algorithm. J Trauma Acute Care Surg. 2020;89:311-9. Doi: 10.1097/ ta.0000000000002773.

26. McIntyre LK, Schiff M, Jurkovich GJ, Weigelt J, Asensio JA, Cogbill TH, et al. Failure of nonoperative management of splenic injuries: Causes and consequences. Arch Surg. 2005;140:563-9. Doi: 10.1001/ archsurg.140.6.563.

27. Peitzman AB, Harbrecht BG, Rivera L, Heil B. Failure of observation of blunt splenic injury in adults: Variability in practice and adverse consequences. J Am Coll Surg. 2005;201:179-87. Doi: 10.1016/j. jamcollsurg.2005.03.037.

28. Smith J, Armen S, Cook CH, Martin LC. Blunt splenic injuries: Have we watched long enough? J Trauma. 2008;64:656-63. Doi: 10.1097/TA.0b013e3181650fb4

29. Bee TK, Croce MA, Miller PR, Pritchard FE, Davis KA, Fabian TC. Failures of splenic nonoperative management: Is the glass half empty or half full? J Trauma. 2001;50:230-6. Doi: 10.1097/00005373200102000-00007.

30. Jeremitsky E, Smith RS, Ong AW. Starting the clock: Defining nonoperative management of blunt splenic injury by time. Am J Surg. 2013;205:298-301. Doi: 10.1016/j.amjsurg.2012.10.022.

31. Plurad DS, Green DJ, Inaba K, Benfield R, Lam L, Putty B, et al. Blunt assault is associated with failure of nonoperative management of the spleen independent of organ injury grade and despite lower overall injury severity. J Trauma. 2009;66:630-5. Doi: 10.1097/TA.0b013e3181991aed.

32. Peitzman AB, Heil B, Rivera L, Federle MB, Harbrecht BG, Clancy KD, et al. Blunt splenic injury in adults: multi-institutional study of the eastern association for the surgery of trauma. J Trauma. 2000;49:177-89. Doi: 10.1097/00005373-200008000-00002. 